\title{
Assessment of Gullibility of Older Patients is Important for their Safety and Health
}

\author{
Andrzej Brodziak ${ }^{1,2 *}$, Renata Zlotkowska ${ }^{1,3}$ and Alicja Różyk-Myrta ${ }^{2}$ \\ ${ }^{1}$ Institute of Occupational Medicine and Environmental Health, Sosnowiec, Poland \\ 2Institute of Medical Sciences, University of Applied Sciences, Nysa, Poland \\ ${ }^{3}$ Faculty of Public Health, Department of Social Medicine and Prophylaxis, Medical University of Silesia, Bytom, Poland
}

\begin{abstract}
The authors consider the state of contemporary knowledge related to notion of gullibility and methods of its assessment. They emphasize that there is almost no publication on this subject in medical literature.

Increased gullibility makes a person vulnerable to manipulations. The gullible people are often victims of scam. Elderly people are particularly vulnerable to scam and fraud. Thus, the frequency and intensity of gullibility and the ways to its assessment are in particular important in the field of geriatric care.

The authors quote some selected items of the proposed self-report measure of gullibility, elaborated recently for evaluations in general population. They argue also that the assessment of the prevalence of gullibility is important for the state of public mental health, because widespread gullibility facilitate manipulations of members of a community and promotions of xenophobic, nationalistic attitudes and populist promises. Then the authors discuss the necessary investigations on the methods of assessment of gullibility among elderly and on the spread of this trait of personality in different age groups of patients.
\end{abstract}

Keywords: Gullibility; Credulity; Naiveté; Self-report measure of gullibility geriatric medicine; Elderly health care; Public mental health

\section{Introduction}

Increased gullibility makes a person vulnerable to manipulations. The gullible people are often victims of scams or frauds. Scam crimes are a significant problem in civil justice procedures and criminal investigations.

The repercussion of gullibility can be especially seen among older people. Elderly people seem particularly vulnerable to scam $[1,2]$.

Thus, the frequency and intensity of gullibility and the ways to assess this vulnerability are in particular a problem in the field of geriatric care and in general in care for the well-being of elderly people [3].

Surprisingly, so far, almost no scientific studies have been attempted to assess the degree of dependence between the age of patients and intensity of gullibility.

Also, the factors that influence the existence of this particular personality trait have not been examined yet extensively.

The purpose of this short commentary is therefore to stimulate the investigations, which will lead to the development of methods detecting increased gullibility in older people. This will make possible to include to the principles of care for the elderly the advices that would reduce the risk of becoming a victim of deceptions. If it were possible to determine methods of belittling credulity, it would also improve the quality of many activities in the field of care for the elderly.

\section{The State of Contemporary Knowledge Related to Notion of Gullibility and Methods of its Assessment}

Contemporary possibility of assessing the degree of gullibility are modest. The scientific deliberations on this subject began with the consideration of the so-called Forer's effect also known as the Barnum effect [4].

Forer's or Barnum's effect is a psychological phenomenon whereby particular person give high accuracy ratings to characteristics of their personality that supposedly were tailored specifically to them but that, in fact were vague enough to apply to many people.
Till recently almost unique scale used in practice to asses gullibility was so called "Social Vulnerability Scale" [3]. The Social Vulnerability Scale was designed to be completed by friends or relatives of people with cognitive impairments or autism. Pinsker et al. maintain that people are more vulnerable to manipulation by reason of impaired memory, diminished executive functioning, and impaired social reasoning skills [3].

There is probably unique scientific article, which presents data related to the difference in level of gullibility between middle-aged and elderly people, however this paper was publish in Japan language and is known to us only from its abstract [5].

A breakthrough work conceived to develop a reliable self-report measure of gullibility for a normal population is the Ph.D. thesis of Alessandra Teunisse, which is accessible on-line [6]

Alessandra Teunisse assumed the following definition of gullibility: "personality trait of gullibility is an acceptance of a false premise in the presence of untrustworthiness cues. As such, the gullible person could be reasonably trusting, while also lacking in an ability or motivation to detect cues of untrustworthiness. Thus, the false belief that the gullible person forms is based on their insensitivity to cues of untrustworthiness".

This researcher remarks also that "One's ability to detect cues could be due to an impairment to Theory of Mind, low social intelligence, fatigue, divided attention, and cognitive busyness (i.e., significantly

${ }^{*}$ Corresponding author: Andrzej Brodziak, Institute of Occupational Medicine and Environmental Health, Sosnowiec, Poland, Tel: +48 3226608 85; Fax +48 32266 11 24; E-mail: andrzejbrodziak@wp.pl

Received February 08, 2018; Accepted February 23, 2018; Published February 26, 2018

Citation: Brodziak A, Zlotkowska R, Różyk-Myrta A (2018) Assessment of Gullibility of Older Patients is Important for their Safety and Health. J Gerontol Geriatr Res 7: 462. doi:10.4172/2167-7182.1000462

Copyright: (C) 2018 Brodziak A, et al. This is an open-access article distributed under the terms of the Creative Commons Attribution License, which permits unrestricted use, distribution, and reproduction in any medium, provided the original author and source are credited. 
increasing working memory load). However, even if the ability to detect the cues is present, motivation has the potential to moderate the ability to detect these cues. For example, a strong desire for love may blind a normally critical person to the warning signs that they are being taken in by a romance scam".

It is necessary to realize that gullibility is a multifaceted feature. It appears from the studies just cited here. Gullibility may encompass some aspects of trust, agreeableness, decreased social intelligence and Machiavellianism [6].

Some researcher considers if gullibility could be the combination of high trust and low social intelligence [7].

Social intelligence is defined as a person's ability to make precise social estimations based upon interpretation of social information.

Gullibility might also be related to Machiavellianism [8]. The essential features of Machiavellianism include hostile distrust and a manipulative social style. Although the relationship between gullibility and Machiavellianism is not clear, the research on scales that could measure Machiavellianism could potentially indicate for existence of gullibility [6].

Alessandra Teunisse performed two empirical studies. As the results of her first study is so called Gullibility Item Pool. It is in fact a scale composed from 70 items, which is accessible on-line [6]. Using the factor analysis, she elaborated then a 35-item scale consisting of four factors named as: Persuadable, Trust, Unassertive, and Unsuspecting, which is also available. Finally, the Trust factor was removed and a short scale composed from 24 items is proposed.

She found that the gullibility is associated with higher levels of agreeableness and lower levels of social intelligence [6]. There was no significant relationship between gullibility and Machiavellianism, or gullibility and trust [6]

\section{A Sample of few Selected Items of the Mentioned Self- Report Measure of Gullibility}

For illustration of the discussed topic we selected the following items taken from the short scale composed from 24 items, proposed by Alessandra Teunisse [6]:

\section{Unsuspecting}

G10 I'm not that good at reading the signs that someone is trying to manipulate me

G12 I'm pretty poor at working out if someone is tricking me

G13 It usually takes me a while to 'catch on' when someone is deceiving me

\section{Unassertive}

G4 I am often put in a situation where I have to pay for others

G6 People often take advantage of my generosity

G38 People often use me to get what they want

\section{Persuadable}

G18 I am probably a little too quick to believe others

G19 My friends think I'm easily fooled

G22 People think I'm a little naïve
G39 When debating an idea, I am easily convinced of another person's point of view

Familiarization with the above questions makes it possible to become aware of the essence of the personality feature called as gullibility.

\section{Discussion}

The scale developed by Alessandro Teunisse is designed to assess the level of gullibility in the general population. It seems that further research is needed to develop a scale for testing older people and elderly patients.

The quoted fragment of Teunisse's scale allows an approximate assessment of gullibility in the elderly. Apart from presenting to the patient the quoted questions, it is possible during conversation with him to counsel guarding him against the consequences of his mental state, especially giving him attention to the abovementioned "ability and motivation to detect cues of untrustworthiness".

It should be noted that recently the importance of the assessment of the prevalence of gullibility for the state of public mental health has been recognized [9]. In a situation where many citizens are significantly gullible it is possible to manipulate easily members of such a community. It is easy then to promote xenophobic, nationalistic attitudes and populist promises. Especially the older people are particularly vulnerable to such manipulations.

It seems that a slightly different, special measurement scale would be needed for the purpose of studying the relationship between the prevalence of the above-mentioned social attitudes and the level of gullibility.

One should also consider differences in the meaning of similar notions such as credulity and naiveté.

The mean level of gullibility is also important for the quality of the results of all teaching programs. Good learning outcomes can only be achieved if the criticism of thinking is a feature considered as valuable $[10,11]$.

\section{Conclusion}

1. The issue of credulity and the methods of its evaluation should be known to people involved in health care of the elderly, because older people are in particular vulnerable to scam and fraud.

2. If a significant number of people in a certain community is gullible, then promoting of xenophobic, nationalist attitudes by people promoting the populist program it's easier. The public mental health is then impaired.

3. Good quality of education requires the promotion of critical thinking.

4. Further research is needed on the methods of assessing the level of gullibility and on the spread of considerable gullibility in different age groups and different clinical situations.

\section{References}

1. Pinsker DM, McFarland K (2010) Exploitation in older adults: personal competence correlates of social vulnerability. Neuropsychol Dev Cogn B Aging Neuropsychol Cogn 17: 673-708.

2. Pachana NA, Byrne GJ, Wilson J, Tilse C, Pinsker DM, et al (2014) Predictors of financial capacity performance in older adults using the Financial Competence Assessment Inventory. Int Psychogeriatr 26: 921-927. 
Citation: Brodziak A, Zlotkowska R, Różyk-Myrta A (2018) Assessment of Gullibility of Older Patients is Important for their Safety and Health. J Gerontol Geriatr Res 7: 462. doi:10.4172/2167-7182.1000462

3. Pinsker DM, McFarland K, Stone VE (2011) The social vulnerability scale for older adults: An exploratory and confirmatory factor analytic study. J Elder Abuse Negl 23: 246-72.

4. Layne C (1979) The Barnum effect: Rationality versus gullibility? J Consulting Clinical Psychol 47: 219-221.

5. Hatta T, Hatta T, Iwahara A, Hatta J, Nagahara N, et al. (2015) Relations among higher brain function, trust, and gullibility in middle-aged and elderly people. Shinrigaku Kenkyu 85: 540-548.

6. Teunisse A (2015) Gullibility: A review of the literature and devising a selfreport measure. Macquarie University Research Online.
7. Greenspan S, Black RS (2001) Credulity and gullibility in people with developmental disorders : A framework for future research. Int Rev Res Mental Retard 24: 101-135.

8. Gurtman MB (1992) Trust, distrust, and interpersonal problems: A circumplex analysis. J Personality Social Psychol 62: 989-1002.

9. Brodziak A, Zlotkowska R, Wolinska A, Rozyk Myrta A (2018) Naiveté the key feature and target of improving population mental health. Environmental Med.

10. Carroll RT (2005) The sceptic's dictionary. Becoming a critical thinker: A guide for the new millennium. Pearson

11. Carroll RT (2006) Teaching Critical Thinking. Retrived from http://skepdic.com/ essays/teachingCT.pdf 